entitled "The safety and efficacy of clozapine in severe treatment-resistant schizophrenic patients in the UK"?

Firstly, their 54 "treatment-resistant" patients were not so treatment-resistant. They had had on average five past schizophrenic episodes, which means they had five times previously got better, to a greater or lesser extent, in response to treatment or without it. Furthermore, a number of unspecified patients were responding to pre-existing medication. Some were so "partially controlled" that it could only be gradually withdrawn and replaced by clozapine, and a few were "permitted" to stay on it and receive clozapine "in parallel" throughout the trial.

Then, the therapeutic results were, to say no more, unimpressive. Over half the cases (28) were outright failures and did not complete the six-month course: one because of suicide; $15(28 \%)$ because they were "uncooperative" or "violated the protocol", which implied they remained too ill to accept clozapine, or retained enough sanity to refuse it; four because "the study drug was ineffective"; and seven (13\%) because of adverse reactions.

In ordinary language, these are outright failures, even though the authors prefer to gloss over them as "early terminations". Of the remaining 26 cases, 19 were still, after six months, "moderately" or "markedly" or "severely" ill, and only 7 (12\% of the whole series) had become "borderline or mildly ill". And of these 26, epileptic seizures developed in five.

Undaunted, the Study Group concludes that these results are "highly encouraging." They even contend, and this after only six months' observation, that their results "clearly show" that clozapine can have long-term benefits for these patients! Were that true, or even plausible, it would have made headlines long ago, since clozapine has been in use for 30 years (McKenna \& Bailey, BJP, January 1993, 162, 32-37).

They should re-examine the forgotten story of insulin coma therapy in schizophrenia (Bourne, 1953; Cramond, 1987). It too was a breakthrough, it too was dangerous as well as extremely costly and, in its heyday of universal use, it produced results far superior to these. And yet, in the end, it was an illusion.

Bourne, H. (1953) The insulin myth. Lancet, 2, 964.

Cramond, W. A. (1987) Lessons from the insulin story in psychiatry. Australian and New Zealand Journal of Psychiatry, 21, 320.

Via M. Bragadin, 6

HAROLD BOURNE

00136 Roma

Italy
Altheimer's disease and Lewy body dementia

SIR: In reference to our study (Förstl et al, BJP, March 1993, 162, 385-392) Liberini et al (BJP, November 1993, 163, 693-694) raise the possibility that responders to cholinesterase inhibitors, and in particular to tacrine, may turn out to show Lewy body pathology. They suggest that the solution to this might come from a post-mortem examination of responders.

As our own tacrine trial was the first to identify the presence of a subgroup of responders, constituting about one-third of those entering the study (Eagger et al, 1991), we have, where possible, attempted to carry out such a post-mortem follow-up. Since only a proportion of all patients maintained contact with our unit in order to obtain continued supplies of tacrine after the cessation of the trial, the sample under such study is liable to be biased. However, it is worth reporting that the first three brains studied, all from 'responders', did indeed show a considerable number of cortical Lewy bodies in addition to numerous plaques, tangles and $\beta$-amyloid deposits. Where it proved possible to obtain frozen tissue from the brains (in two out of the three cases) cholinacetyltransferase levels measured in Dr Elaine Perry's laboratory were found to be even lower than those in pure Alzheimer's disease.

Thus, although it is too early to reach a definite conclusion on the limited number of post-mortems carried out so far, preliminary results suggest that Liberini et al's prediction may well turn out to be correct.

EAGger, S., LeVy, R. \& SAHAKian, B. (1991) Tacrine in Alzheimer's disease. Lancet, 337, 989-992.

Institute of Psychiatry

RAYMOND LEVY

De Crespigny Park

Denmark Hill

London SE5 8AF

\section{Anorexic siblings}

SIR: It is generally agreed that anorexia nervosa has a multi-determined aetiology (Garfinkel \& Garner, 1982) and intrafamilial factors are rightly regarded as of particular importance (Hsu, 1990). Close attention is usually paid to the relationship between the sufferer and his/her parents (for example, see Bruch, 1988). I suspect, admittedly on anecdotal grounds, that the effects of siblings on each other may also be of importance, and recent considerable media publicity surrounding the 'diet twins' (for example, Sunday Mirror, 19 September 1993, p. 24: "Story all 
Britain is Talking About") illustrates its general interest.

Strober et al (1990) postulate genetic factors in the causation of anorexia nervosa and obviously this is also a possibility in the case of such identical twins.

Theander (1970), Crisp et al (1980) and Hudson et al (BJP, February 1983, 142, 133-138) all agree on a $6-7 \%$ sibling risk in anorexia. The incidence of anorexic siblings may, however, be greater than some members of a family know or are prepared readily to admit.

Having been 'sensitised' by my contact with the family ' $\mathbf{X}$ ', I found that no fewer than five of the 25 anorexic/bulimic patients referred to me over a oneyear period turned out to have sisters who were also sufferers. In two of the 13 anorexic patients, their own condition had apparently been triggered by their anorexic sister's slimness (and perhaps concern and attention), and in another anorexic girl, her older sister's anorexia had been unknown to her. One bulimic girl had a bulimic sister (unknown to her parents) and another had a sister whose past bulimia was "a family secret" and only admitted after several interviews.

Case report. Family ' $X$ ' had four children: daughters ' $B$ ', 'C' and ' $D$ ', and ' $D$ 's' twin brother ' $E$ '.

B was referred in 1974, at the age of 20 years, with a history of typical anorexia nervosa since the age of 16 . Her pre-morbid weight was $60.8 \mathrm{~kg}$ (lowest weight $41.3 \mathrm{~kg}$ ) at a height of $1.65 \mathrm{~m}$. Her illness had apparently been triggered by jealousy of C's slimness. B recovered completely after treatment.

$C$ was referred in 1980, at the age of 23 years, again with a typical history of anorexia since the age of 16 . Her premorbid weight was $60.33 \mathrm{~kg}$ (lowest weight $27.7 \mathrm{~kg}$ ) at a height of $1.7 \mathrm{~m}$, and her anorexia had been triggered by the onset of B's anorexia. After treatment, $\mathrm{C}$ improved (weight $51.3 \mathrm{~kg}$ ) but she married, moved to another city, and lost touch. Sadly, she apparently died the following year.

D, B's and C's younger sister, was referred in 1982, at the age of 17 years, with typical anorexia nervosa, apparently triggered by C's death. At referral her weight was $39.9 \mathrm{~kg}$ (normal weight $50.8 \mathrm{~kg}$ at a height of $1.69 \mathrm{~m}$ ). She recovered with treatment, although she continued to be underweight and became a vegetarian.

B's and C's younger brother, and D's twin, E, was referred in 1986. Although his symptoms did not reach strict diagnostic criteria of anorexia nervosa, he had developed numerous curious rituals and beliefs about eating. He feared 'fatness' and had lost some weight to $57.6 \mathrm{~kg}$ (normal weight $68.0 \mathrm{~kg}$ at a height of $1.78 \mathrm{~m}$ ). His symptoms had apparently been triggered off by the development of his twin's (D's) anorexia. He recovered completely with treatment and he, $B$ and $D$ remained well at enquiry in 1988

BruCH, H. (1988) Conversation with Anorexics (eds D. Czyzewski \& M. A. Suhr). New York: Basic Books.
Crisp, A. H., Hsu, L. F. G., Harding, B., el al (1980) Clinical features of anorexia nervosa-a study of a consecutive series of 102 female patients. Journal of Psychosomatic Research, 24, 179-191.

GARFINKEL, P. E. \& GARner, D. M. (1982) Anorexia Nervosa-A Multidimensional Perspective. New York: Brunner-Mazel.

Hsu, G. L. K. (1990) Eating Disorders. New York: Guilford Press.

Strober, M., LAmpert, C., Morrell, W., et al (1990). A controlled family study of anorexia nervosa. Evidence of family aggregation. International Journal of Eating Disorders, 3, 239-253.

THEANDER, S. (1970) Anorexia nervosa. A psychiatric investigation of 94 patients. Acta Psychiatrica Scandinavica, Suppl. 214

I am particularly grateful to Gerald Russell, Janet Betteridge and Liz Whitehouse.

The Woodbourne Clinic

Peter Hall

Woodbourne Road

Edgbaston

Birmingham B17 8BY

Neuroleptic malignant syndrome and carbamazepine?

SIR: Neuroleptic malignant syndrome (NMS) refers to a serious symptom complex which is sometimes seen in association with neuroleptic drugs. Symptoms include hyperthermia, muscle rigidity, altered mental status, autonomic dysfunction, elevated creatine phosphate kinase and leucocytosis. The pathomechanism has not yet been clarified but it has been thought that NMS develops after an acute dopaminergic transmission block in the basal ganglia and the hypothalamus due to treatment with dopamine receptor antagonists or withdrawal of dopamine receptor agonists (Weller \& Kornhuber, 1992).

The association between carbamazepine (CBZ) and NMS has been suggested by O'Griofa \& Voris (1991). However, the following should be kept in mind. CBZ is an anticonvulsant drug which is also used in psychiatric disorders and is therefore often given in combination with neuroleptic medication. The mode of action of CBZ is not yet completely understood, but stabilisation of the neuronal membranes by acting on the sodium and potassium channels most likely play a role (Macdonald, 1989; Schmutz, 1992). To our knowledge, there is no known action of $\mathrm{CBZ}$ on the dopamine receptor, so that CBZ is unlikely to be directly involved in the pathomechanism of NMS. Nevertheless, the records of CIBA contain 15 cases of NMS in which $C B Z$ was part of the therapy. In most of these cases concomitant neuroleptic treatment could be held responsible for the development of NMS.

CBZ has been on the market for more than 20 years. To our knowledge the first case of NMS in 